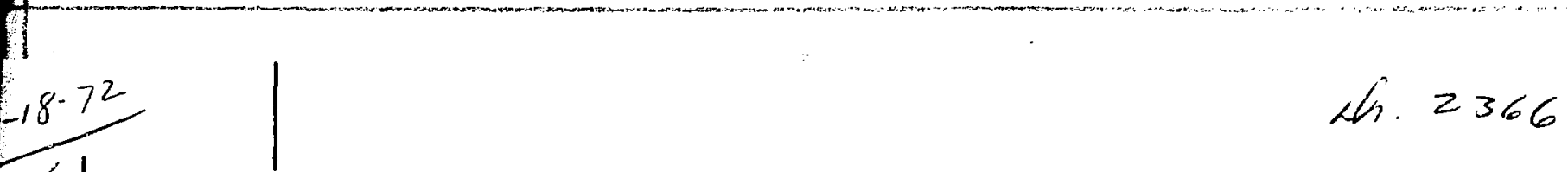

2.61 LA.5008

History of the

Plutonium Bioassay Program at the Los Alamos Scientific Laboratory, $1944-1972$ 
This report was prepared as an account of work sponsored by the United States Government. Neither the United States nor the United States Atomic Energy Commission, nor any of their employees, nor any of their contractors, subcontractors, or their employees, makes any warranty, express or implied, or assumes any legal liability or responsibility for the accuracy, completeness or usefulness of any information, apparatus, product or process disclosed, or represents that its use would not infringe privately owned rights.

Printed in the United States of America. Available from National Technical Information Service

U. S. Department of Commerce 5285 Port Royal Road

Springfield, Virginia 22151

Price: Printed Copy \$3.00; Microfiche $\$ 0.95$ 
LA.5008

UC-41

ISSUED: October 1972

\section{History of the \\ Plutonium Bioassay Program at the Los Alamos Scientific Laboratory,}

$1944-1972$

by

Evan E. Campbell

Morris F. Milligan

William D. Moss

Harry F. Schulte 
HISTCRY OF THE PLUTONIUM BIOASSAY PROGRAM AT THE

LOS ALAMOS SCIENTIFIC LABORATORY, 1944-1972

by

Evan E. Campbell, Morris F. Milligan, William D. Moss, and Harry F. Schulte

\section{ABSTRACT}

A chronological description is given of the methods used in the plutonium bicassay program at Los Alamos. Methods of urine-sample collection, radiochemical separation, and counting are described briefly.

\section{INTRODUCTION}

Early in 1944, the late Wright H. Iangham instituted at the Los Alamos Scientific Iaboratory a program for the collection of urine samples from employees handling plutonium, and for determining the plutonium in those samples. The aim at the time was to acquire evidence of actual exposure as an aid in engineering control of the working enviromment. Sampie contamination, difficulties in separating plutonium from the samples, and the inferior alpha-counting systems of that date, all tended to limit severely the number of analyses and the vaIidity of the results.

The overall plutonium bioassay program has been changed from time to time, and this document describes the changes chronologically, dividing them for convenience of discussion into three areas: urine-sample collection, radiochemical separation, and alpha-counting systems.

\section{URINE-SAMPLE COLLECTION}

\section{Early 1944}

Urine samples were collected on a random basis at work after the employee had passed through a decontamination shower.
The samples were collected principally to assist in the development of a method to separate plutonium from urine. Data are recorded for only a few urine samples during this period.

March 1944

Urine samples were collected on a 24-h basis; all urine voided during the day was collected in "clean" areas after decontamination and a clothing change. The single bottle was taken home in the evening and returned the following morning to complete the 24-h collection. Occasional extremely high results were probably caused by artifactual contamination of the samples, plutonium and polonium being handled in the same work area. One of the reasons advanced for the construction of a new plutonium-handing facility was that the bioassay procedure couid not at that time differentiate adequately between polonium and plutonium. Spring 1945

A program was instituted to "insure" collection of contamination-free urine samples. The Health-Pass Ward procedure provided the employee 2 days away from the working environment; this time was to be 
spent on vacation away from Los Alamos. The employee then reported to the hospital, where the Health-Pass ward was lccated. The employees stripped, showered, and went through a change rcom in an effort to keep the area as free of contamination as possible. The employee was asked to discard his first voiding upon entering the ward and to collect all voidings for the next $24 \mathrm{~h}$. The single bottles were provided with funnels, and the name of each employee was marked on the side. January 1948

Owing to the remarkable expense (in both time and money) involved in liberating employees for 2 days with pay, the Healthpass lard procedure was modified. The only time off work was the 1 day during which the urine sainple was collected in the hospital. February 1952

The necessity of sampling more employees more frequently, and the unpleasantness of collecting urine for $24 \mathrm{~h}$ in a single bottle, led to a complete revision of the collection procedure. The Health-Pass Ward was eliminated, and each sampled employee was provided with a "lunch kit" in which he was requested to collect the last voiding before retiring and the first voiding upon arising for 2 consecutive days. The "lunch kit" was a steel, hinged, thermos-bottle type lunch box containing three disposable, 1-pint, glass bottles. Th o object of the procedure was to collect the equivalent of a real 24-h sample.

The "lunch kits" were picked up from the Health Physics monitor as the employee left the laboratory, and were expected to be returned on the third day. Upon receipt in the bioassay laboratory; the kits were washed, sterilized, filled with new 1-pint bottles, and returned to the Health Physics monitor.

Unfortunately, the concept of collecting four voidings in three bottles was not accepted with grace by some employees, and some samples received obviously represented no more than three voidings instead of the four requested.
January 1958

In an effort to solicit rore favorable employee cooperation, a four-bottle kit was introduced. The kit was a disposable cardboard carton with a handle, similar to those used to market many canned and bottled items; it contained four 1-pint disposable glass bottles. Use of this kit obviated the necessity of cleaning and reuse of any item, again reduced potential contamination, and was more sanitary. The bottles provided one container for each voidiilg requested, and the contents more nearly approached trie volume of a true 24-h sample.

This method is still in use today to provide urine samples from all employees scheduled for routine plutonium bioassay. The urine sampling and analysis program was reviewed in $1969 ; 1$ the study indicated that the individual analytical results were distributed log-normally with a jeometric standard deviation of 1.9 .

In recent years, volume and specific gravity have been determined for each 24-hequivalent urine sample; creatinine is determined on selected samples. All scheduling is now carried out on electronic dataprocessing equipment that produces the notice to the employee, the urine-kit label, the laboratory notebook page, and the necessary data cards for processing the analytical result.

In an effort to investigate the relationship of plutonium excretion and time, special samples are occasionally collected. Such samples, requested only of cooperative employees known to excrete measurable amounts of plutonium, represent all voidings during a 3-day period. The selected employee is provided with three kits; each of the twelve bottles has on its lid a sticker with a 24-h clock printed on it, and the employee is asked to mark the lid to indicate the period over which the urine in that bottle was collected.

When the kits are returned to the bioassay laboratory, the analyst selects the set of voidings that most closely represents 
a 24-h sample; measures the volume, temperature, and specific gravity of each individual sample and of the combined 24-h sample; and proceeds with the r.nalysis.

studies on such carefully timed samples have suggested that it is possible to correct urine samples from the employee population of this laboratory to a calculated 24-hequivalent sample, the correction being valid if the actual urine volume approximates that of a 24-h sample.

\section{RADIOCHEMICAL SEPARATION}

Early 1944

The first procedure used for determination of plutonium in urine was simply an evaporation and drying technique. No discussions of the procedure are recorded in available notebooks of the time. Urine was evaporated to diyness in the presence of nitric acid, the residue was ashed to whiteness with additional nitric acid, and the ash was tranjferred to stainless steel plates. The plates were counted on a gasflow counter of unknown geometry and background. It is probable that urine samples were occasionally contaminated with significant amounts of polonium.

Fall 194:

Wright Langham described a procedure for determination of plutonium in urine. 2 The urine was evaporated to dryness in the presence of nitric acid; after the ash was whitened by heating with additional nitric acid, it was dissolved in dilute acid, and the plutonium with iron carrier was extracted by cupferron in chloroform. The chloroform extract was evaporated to dryness, the residue was ashed by heating with nitric and perchloric acids, and the plutonium was carried from a dilute acid solution on lanthanum fluoride. The lanthanum fluoride precjpitate was centrifuged down and slurried on 1.25-in. diameter stainless steel plates.

Comments in the notebooks indicate that significant losses may have occurred during the evaporation with nitric acid because of occasional violent exothermic raactions, called "flares." Recoveries of 82.38 with a standard deviation of 19.48 were used to interpret the data.

October 1949

The radiochemical-separation procedure was changed to the bismuth phospluate-lanthanum fluoride serial coprecipitation procedure described by Russell. ${ }^{3}$ Urine was evaporated to dryness in the presence of nitric acid. The residue was whitened by hearing with additional nitric acid and dissolved in dilute acid from which plutonium was coprecipitated with bismuth phosphate. The bismuth phosphate precipitate was dissolved in dilute acid from which plutonium was again coprecipitated, this time on lanthanum fluoride. The lanthanum fluoride coprecipitation was repeated, and the final precipitate was slurried on a 1.25-in. diameter stainless steel plate preparatory to counting.

Radiochemical recoveries during this period were $67 \pm 21 \%$. Investigation suggested that it was possible to eliminate the lengthy and expensive evaporation of large volumes of urine and nitric acid. Instead, plutonium could be carried directly on a voluminous precipitate of alkaline-earth phosphates and bismuth phosphate. This was accomplished by acidifying the urine with nitric acid to destroy any weak complexes of plutonium with urinary constituents, adding a bismuth carrier, and making the entire urine solution alkaline with ammonia. This procedure gave more constant plutonium recoveries without affecting the blank. The rest of the procedure was unchanged. January 1957

In an effort to increase the sensitivity of the overall bioassay procedure, a change was effected to the nuclear-track method of alpha counting as described by Schwendiman and Healy. 4 This was concurrent with a complete change in radiochemical-separation techniques. The method included a 
bismuth phosphate precipitation, Eollowed by an alkaline earth-phosphate precipitation. The latter precipitate was ashed, the residue was dissolved in dilute acid, and the lanthanum fluoride coprecipitation was used, followed by a thenoyltrifluoroacetone (TTA) purification step. A back-extract of the organic phase was evaporated to dryness and dissolved in a suitable electrolyte, and plutonium was electrodeposited on 0.5-in. diameter stainless steel disks preparatory to al.pha counting.

Urine "blanks" collected from bioassaylaboratory personnel were found to contain $0.007 \pm 0.005 \mathrm{dis} / \mathrm{min}$ (average \pm 1 sigma) with recoveries of $70.7 \pm 17.28$ (average \pm 1 sigma) during 1959-66.

1963

A comparatively simple ion-exchange separation procedure ${ }^{5}$ superseded the coprecipitation-TTA procedure. Plutonium was carried directly from the urine on an alkaline earth-phosphate precipitate. The precipitate was ashed with nitric acid and dissolved in 7.2M nitric acid. From this solution, plutonium was separated on an anion-exchange resin (BioRad $A G 1 \times 2$ ). Plutonium retained on the column was reduced with hydroxylamine and hydriodic acid and eluted with dilute hydrochloric acid. The plutonium-containing eluate was evaporated and dissolved in a suitable electrolyte, and the plutonium was electrodeposited for nuclear-track alpha (NTA) counting. The average recovery for this period was $84 \pm 148$ (average \pm 1 sigma). In 1972, the method described above has been modified. Hydrogen peroxide in small quantities is added to the ash solution before the ion-exchange step to ensure formation of tetravalent plutonium; elution is accomplished with $0.36 \mathrm{M}$ HCL-0.01M HF.

The advent of alpha-spectrometry equipment has allowed the use of internal standards. The first plutonium isotope was ${ }^{236} \mathrm{Pu}$, which prover rerarkably helpful for several years. Investigations have shown that ${ }^{242} \mathrm{Pu}$, rather than ${ }^{236} \mathrm{Pu}$, is more useful for two reasons. First, the comparatively short half-life of ${ }^{236} \mathrm{Pu}$ and the growth of alphaemitting daughters into it present problems in calibration and purification. Second, use of ${ }^{242} \mathrm{Pu}$ enables the laboratory to measure ${ }^{238} \mathrm{Pu}$ with less interference from "tailing" of the characteristic 236 peak when less than perfect plates have been prepared by electrodeposition. Recovery factors average about $70 \%$.

\section{ALPHA-COUNTING SYSTEMS}

$\underline{1944}$

The first vacuum-tube, open-window, gas-flow proportional counter used for counting plutonium in urine ash apparently had a background of approximately 30 counts per minute $(\mathrm{c} / \mathrm{min})$. The counter efficiency was not known, and the problems of self-absorption must have been treriendous.

Spring 1945

Six Simpson alpha counters were received in May 1945. These proportional counters hac been constructed by Hallicrafters for the Chicago Metallurgical Laboratory, and as originally received had backgrounds of about $1 \mathrm{c} / \mathrm{min}$ and efficiencies of 48 to $50 \%$. Modification of these counters, chiefly lining the counting chamber with electrolytic copper foil, reduced the backgrounds to about $0.1 \mathrm{c} / \mathrm{min}$. Other similar counters from Nuclear Measurements Corporation were acquired, and by 1955, 16 counters were being continuously used, an installation that required the services of a fulltime electronics technician and counting technician for maintenance and operation. All samples were prepared on 1.25-in. diameter stainless steel dishes and were counted overnight $(1000 \mathrm{~min})$.

1957

The NTA method of counting plutonium was adopted because of its increased inherent sensitivity and because it involved no electronic equipment with the consequent problems of maintenance. The principle involved in NTA counting was exposure of an 
emulsion sensitive to alpha particles t:o plutonium electrodeposited on 1/2-in. diameter stainless steel plates. After exposure, usually about $10,000 \mathrm{~min}$, the photcgraphic emulsion was developed, fixed, and examined under a microscope to determine the number of tracks. Strict control of exposure conditions and of area counted yielded results of considerable sensitivity and dependability. The background of the NTA method was about $0.005 \mathrm{dis} / \mathrm{min}$, and the lower limit of sensitivity as determined with blank urine samples was estimated to be 0.05 dis/min per sample at the 998 confidence level. It is interesting that even with this increased sensitivity, no new exposures were discovered, and previously determined urinary-excretion levels were confirmed.

$\underline{1966}$

Eight scintillation counters employing the alpha-counting technique described by Hallden and Harley ${ }^{6}$ were constructed by the LASL Electronics Group, P-1. These electronic counters were simple and easy to maintain. The electrodeposited plutonium was placed in contact with a silver-activated zinc sulfide phosphor coated on a thin, 1/2-in.-diameter plastic sheet. A suitable photomultiplier tube was placed in contact with the plastic sheet, through which it "saw" the flashes resulting from impingement of alpha particles on the phosphor. This procedure precluded the possibility of contaminating the active volume of the detector, and gave low and reproducible background counting rates, generally $0.01 \pm$ $0.006 \mathrm{c} / \mathrm{min}$ with an efficiency of $45 \%$. Moss and Campbel1 ${ }^{7}$ have compared the NTA counting technique and the zinc sulfide scintillation counter.

1967

During 1966, many of the plates counted by the NTA method and on scintillation counters were recounted using an alpha spectrometer. When sufficient confidence in alpha spectrometry had been established, two 400-channel analyzers with four detectors for each unit were acquired and put in operation. Alpha spectrometry affords two advantages: the possibility of measuring ${ }^{238} \mathrm{Pu}$, an isotope of increasing interest, and the possibility of determining the recovery or yield of the radicohemical steps by use of an internal standard, ${ }^{236} \mathrm{Pu}$. When silicon surface-barrier detectors are used and operation is at a constant efficiency of $27 \%$, the background for each flutonium isotope is $0.003+0.003 \mathrm{c} / \mathrm{min}$.

When the internal ${ }^{236} \mathrm{Pu}$ standard was used, it became evident that recoveries for yields) from individual urine samples may differ significantly even when run at the same time under the same conditions.

The external controls used previously may have been fortuitously high or low depending upon several factors, including the selection of the individual providing a "blank" urine sample.

Because internal control was effective in determining yields, blank urine samples were of little value in attempting to evaluate the significance of results. Reagent blanks, however, may be significant, and they were run regularly, as a matter of prudence. These blanks seldom exceeded the upper limit of the confidence level of the counter background.

$\underline{1971}$

A 16-detector alpha-spectrometer system was installed, together with a multichannel analyzer. A cumulative 3-month average background spectrum was used for conversion of gross counts to net counts. A similar cumulative-average detector efficiency, determined daily on each detector, was used to convert net counts to disintegrations. An efficiency of $27 \%$ was maintained in each 12-channel band, measuring plutonium 236, $238,239-40$, and 242, respectively.

Input data to the computerized datahandling system included the volume of the sample, its specific gravity, and the amount of ${ }^{236} \mathrm{Pu}$ activity added to it. The slope of the low-energy side of the ${ }^{236} \mathrm{Pu}$ peak was computed, and if the spectrum was so 
degrated that the slope was less than 0.67 the results, were considered not completely valid. Rer:overies of $<408$ are not used.

\section{ACKNOWLEDGMENTS}

All if the early work described here, incliding application of the cupferron method of sepiarating plutonium, was under the direction of the late wright $H$. Langham. Use of the bismuth phosphate-lanthanum fluoriae coprecipitation method was instituted uruaer th: direction of Morris F. Milligan, and the conversion to nuclear-track counting was effected by William D. Moss. Evan E. Campbel: hus directed the program during all the latier changes, and has participated directly in the development of improved anionerchance procedures for plutonium separation and of alpha-spectrometric techniques.

Asknowledgments are given to the LASL Electronics Group, P-1, for developing and scristructing much of the electronic equipment ased in the bioassay program; to Leo $\mathrm{J}$. Narr for conceiving and implementing the idea of upgrading gas-flow proportional counters by installing disposable chamber inings of electrolytic copper foil; to Harold $M$. Ide for aid in preparing and maintaining the alpha-spectrometic equipment now in use; to Ivan $K$. Kressin for development of the ion-exchange method now in use; and, finslly, to the 25 to 30 chemical technicia.ss who have, over the years, assisted in the radiochemical separation of plutonium Erom an ocean (or at least a Great Lake) of hurnan urine.

\section{REFERENCES}

1. W. D. Moss, E. E. Campbell, H. F. Schulte, and G. L. Tietjen, "A Study of the Variations Found in plutonium Urinary Data," Health $\mathrm{Ph}$ 's. 17, 571-578 (1969).

2. W. H. Langham, "Determination of Plutonium in Human Urine," Los Alamos Scientific Laboratory, USAEC Report MDDC-1555 (August 1947).

3. E. R. Russell, "Procedures for the Determination of Plutonium in Human Urine," University of Chicago Metallurgical Laboratory report MUC-ERR-156 (October 1945).

4. L. C. Schwendiman and J. W. Healy, "Nuclear-Track Technique for Low-Level $\mathrm{Pu}$ in Urine," Nucleonics 16 , No. 6,78 (1958).

5. E. E. Campbell and W. D. Moss, "Determination of Plutonium in Urine by Anion Exchange," Health Phys. 11, 737-742 (1965).

6. N. A. Hallden and J. H. Harley, "An Improved Alpha-Counting Technique," Anal. Chem. 32, 1861 (1960).

7. W. D. Moss and E. E. Campbel1, "The Determination of Low Level Plutonium Activity; Autoradiographic Techniques Vs. Scintillation counting," llth Annual Bio-Assay and Analytical Chemistry Meeting, USAEC Conf-651008, October 1965. 